\title{
Application of Local Current Pulses for Determination and Control of Residual Stresses
}

\author{
Leonid Lobanov, Vyacheslav Pivtorak, Nikolay Paschin, Viktor Savitsky*, \\ Galina Tkachuk
}

\author{
E.O.Paton Electric Welding Institute, the National Academy of Sciences of Ukraine,
} 11, Bozhenko str., Kyiv, 03680 Ukraine

\begin{abstract}
Keywords: Non-destructive residual stresses determination, residual stresses relaxation, high density pulsed electric current, electrodynamic treatment, welded joints, ESPI.
\end{abstract}

\begin{abstract}
An electrode system for inducing a high density pulsed electric current (PEC) into the material for residual stresses (RS) relaxation has been proposed. A new non-destructive technology for determination of RS using electron speckle interferometry in combination with a local PEC treatment has been developed. Application of PEC at increased power parameters was investigated for control of stressed state of welded structures used in aircraft engineering. Results of practical application of the developed technologies and equipment are presented.
\end{abstract}

\section{Introduction}

Residual stresses are an important factor that has influence on the strength, quality and operational characteristics of welded structures. The problem of residual stresses has become especially urgent now that the leading branches of the industry started widely using high-strength steels and light alloys to manufacture welded structures with high precision, reliability and durability demands.

At present significant progress has been made in developing methods and means for determination and control of residual stresses [1-3]. The hole-drilling method found wide application in the study of residual stresses. The specialists at E.O.Paton Electric Welding Institute proposed residual stress determination by combined use of holographic interferometry and drilling a hole [4]. In recent works other researchers also used holographic interferometry [5-7]. The progress of computer engineering allowed developing high-efficient methods for residual stresses determination using electron speckle-interferometry (ESPI) and blind hole drilling [8-10]. They provide sufficiently wide opportunities for revealing local features of residual stress distribution. But drilling even small holes creates certain limitations for stress state investigation of structures for which any damage is unacceptable. Therefore, the development of non-destructive methods for residual stresses determination is important.

\section{Application of a local high-density PEC treatment for relaxation of residual stresses}

At E.O.Paton Electric Welding Institute a new nondestructive method for residual stresses relaxation has been developed. The method suggests inducing a local high-density electric current pulse $\left(10^{7}-10^{10} \mathrm{~A} / \mathrm{m}^{2}\right.$ and $10^{-4}-10^{-2} \mathrm{~s}$ duration) through the material. The current changes according to a definite law, and its passage through the metal causes electrodynamic processes that result in change of dislocation density and accordingly in local relaxation of residual stress [11]. It is known that such electric current pulses don't lead to significant heating of the object [12]. The schematic of the proposed method is shown in Fig. 1. For its realization a compact device, which allows generation of high-density current pulses, and a special electrode system were designed. 


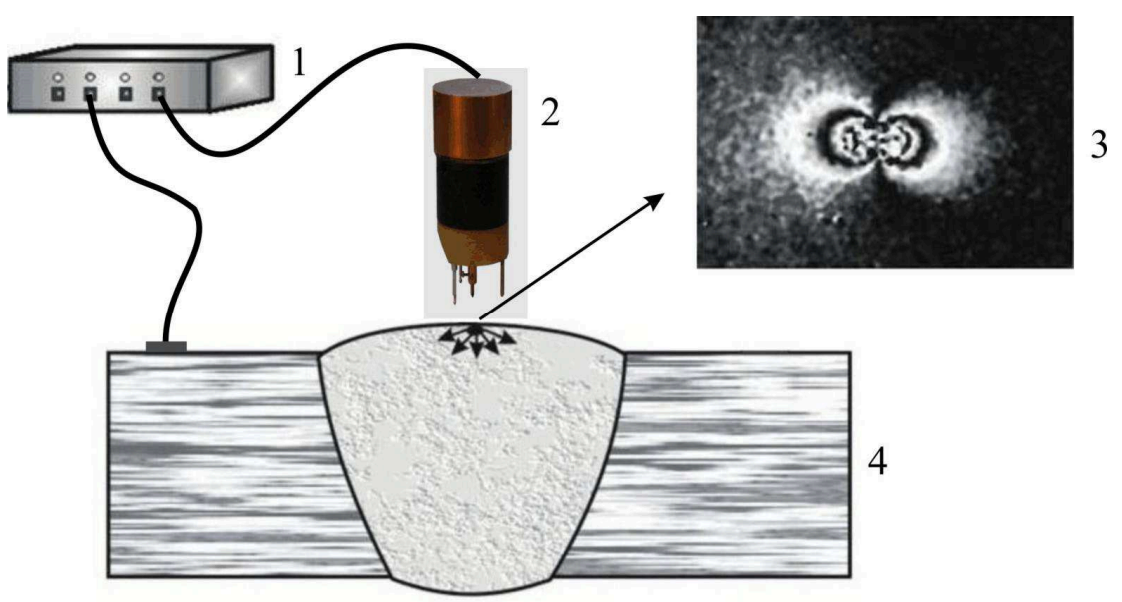

Fig. 1: Schematic representation of a local PEC treatment for residual stresses relaxation: 1 high-density electric current pulse generator; 2 - electrode system; 3 -interference fringes registered at the current introduction area; 4 - welded joint.

\section{Non-destructive determination of residual stresses based on ESPI and a local PEC}

The electron speckle-interferometry in the combination with the hole-drilling method can be used for fast and accurate determination of residual stresses [9, 10]. The ESPI method for residual stresses determination is based on the application of the optical scheme of the speckleinterferometer in which the investigated object section is illuminated under the same angle symmetrically from two directions, so that it is possible to determine the in-plane components of the displacement vector, which characterize the deformation of the object. The displacements, caused by relaxation of residual stresses in the bulk material due to drilling of the blind holes, are measured using the ESPI method. The data of the displacements, measured in the points along the circle with diameter $\mathrm{AB}$ (Fig. 2, a) and located at a certain distance $\left(2.5 r_{0}\right)$ from the center of the drilled hole of radius $r_{0}$, are used for determination of residual stresses using derived formula [10].

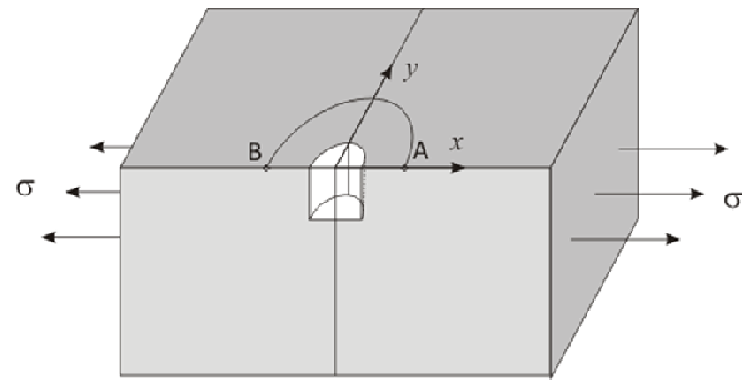

a)

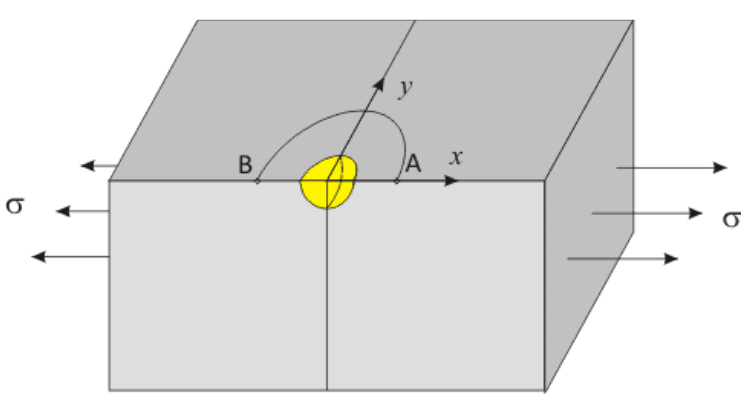

b)

Fig. 2: Scheme of residual stresses determination using ESPI combined with drilling a hole (a) and a local PEC treatment (b).

After the current pulse is induced into a local area of the test object, residual stresses in that region are relieved causing displacements at nearby points. Stress relaxation volume has a hemispherical shape with a diameter up to $1 \mathrm{~mm}$ and its size depends on current impulse density (Fig. 2, b). The displacements in the points along the circle with diameter AB are measured with an ESPI-device developed by E.O. Paton Electric Welding Institute (Fig. 3). A local PEC treatment causes formation of interference fringes, recorded by ESPI, similar to interference patterns registered after drilling of a small blind hole. Measurement is carried out as follows. A speckleinterferometer is mounted on the object's surface. The surface is illuminated by coherent laser beams. The reflected light wave characterizing the initial state of the test area is recorded into computer memory using a CCD camera. After stresses are relieved with a local high-density current 
pulse, a reflected light wave is recorded into computer memory again. Digital processing of these light waves results in an interference fringe pattern that contains information about the deformation and residual stresses in the selected area.

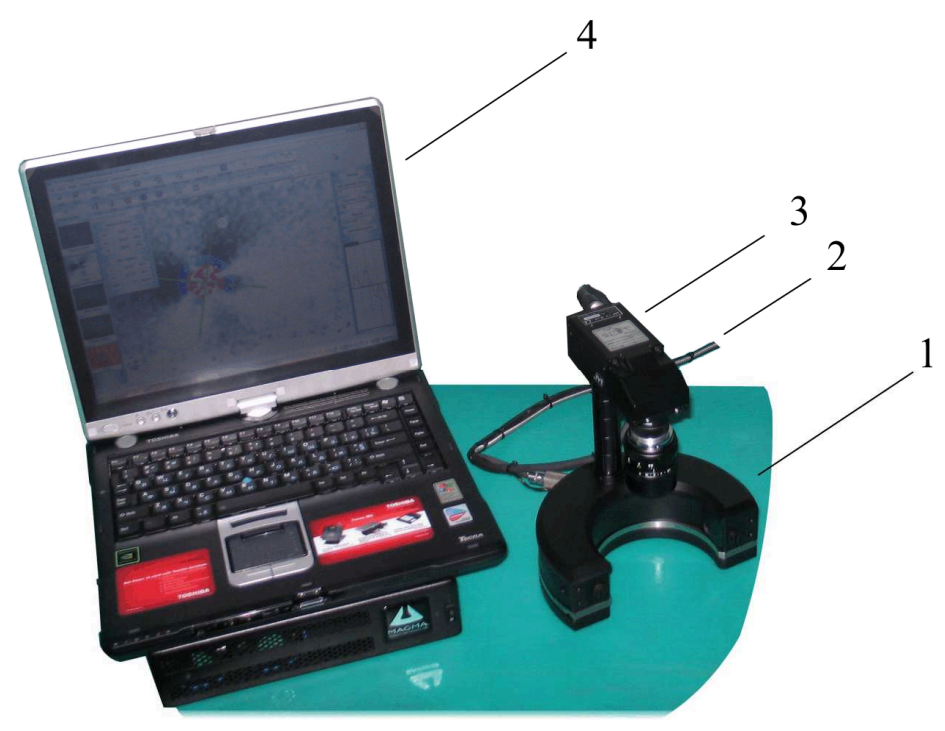

Fig. 3: Portable speckle-interferometer measuring system: 1 - speckle-interferometer; 2 - fiber and cables; 3 - CCD-camera; 4 - computer.

Experiments on a fish-bellied beam of aluminum alloy $\mathrm{AMg} 6$ were carried out to assess the stress relaxation effect of local current pulses (Fig. 4). Loading this beam with a concentrated force applied to its free end allowed creating compressive and tensile stress of different levels, constant throughout the beam length. A high-density PEC with specified parameters was induced to the selected points of the test item along the A-A cross-section. The displacements, caused by stresses redistribution after a local PEC treatment, were measured with the above mentioned ESPI device. Figure 5 shows interference fringes that characterize the displacements which resulted from inducing a local high-density PEC into the cross-section points of the test beam with different stress values. Interferograms demonstrate that displacements in the vicinity of the treated points depend on the stress levels.

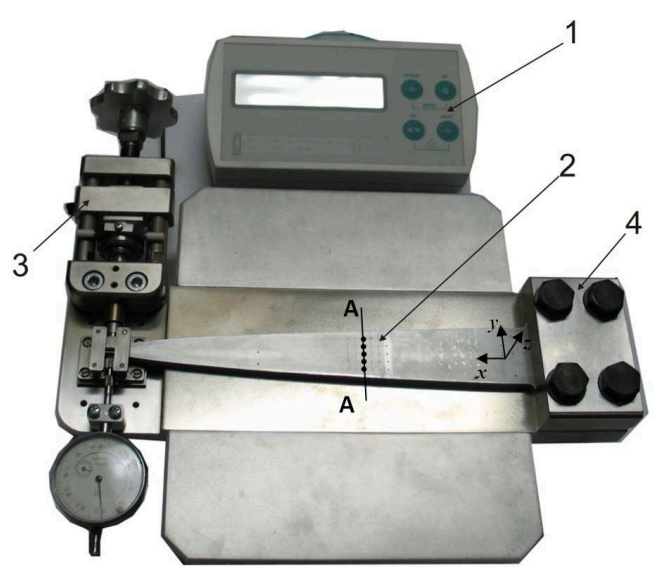

Fig. 4: Loading device with fishbellied beam: 1 - digital indicator; 2 fish-bellied beam; 3 - mechanical loading unit; 4 - beam fixation unit.

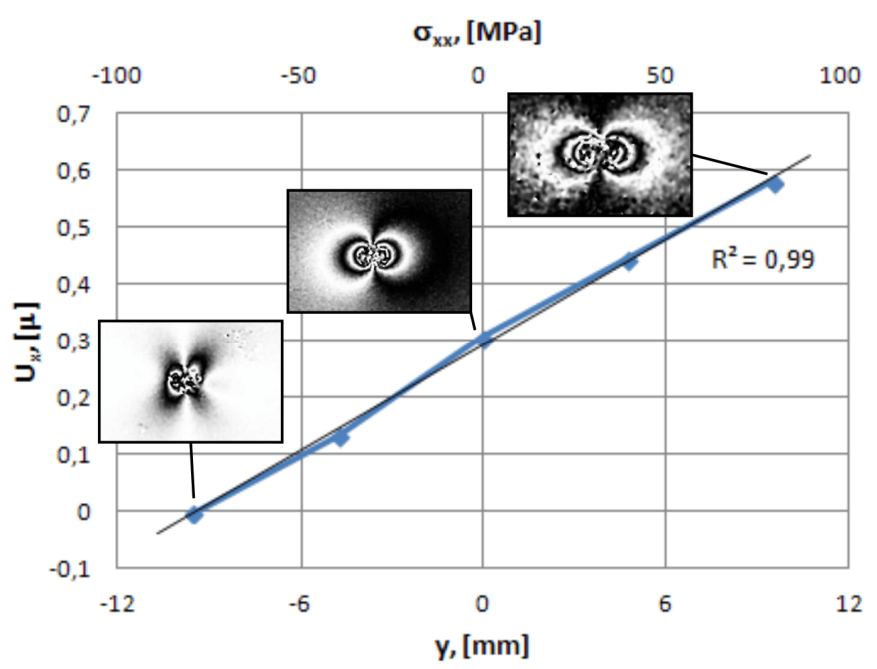

Fig. 5: Dependence of displacements on level of stresses $\sigma_{x x}$, measured by ESPI at $1.25 \mathrm{~mm}$ distance from point of current pulse inducing. 
The displacements values at points A (see Fig. 2, b), as well as the stresses values, are changed linearly along the beam's cross-section (Fig. 5). However, there is an initial effect of the electrodynamic impact of the PEC in the point at the beam's neutral axis, where stresses are equal to zero. Therefore, the following function for determination of residual stresses has been proposed:

$$
\sigma_{x x}=\psi\left(U_{x}-U_{x 0}\right) .
$$

where $\sigma_{x x}$ is the stress value, $\psi$ is a parameter which depends on the object's material and energy characteristics of the electrode system, $U_{x}$ is the displacement measured by ESPI method in the chosen point of the PEC treatment zone and $U_{x 0}$ is the initial displacement in the same point caused by the PEC treatment in the material without residual stresses.

Parameters $\psi$ and $U_{x 0}$ are experimentally determined from displacement data obtained on a fishbellied beam for each material and energy characteristics of the electrode system (Fig. 5).

Thus, the experiments showed that high density electric current pulses could be applied to result in a local relaxation of residual stresses similar to hole drilling. This effect is used for developing the new non-destructive technology for determination of residual stresses, based on measuring of displacements by ESPI in the vicinity of a local high density PEC treatment and calculating stress values according to formula (1).

\section{Controlling residual stresses and deformation using an electrodynamic treatment}

Using an electrode system and a power supply unit with higher energy parameters allows reducing residual stresses and deformation of welded joints. To assess the effect of electrodynamic treatment (EDT) on the stressed state of welded structures, the experiment was carried out on a welded butt joint of AMg6 alloy. Plates with dimensions 450x220x4 mm were welded along the longitudinal edge in automatic mode for one pass, using a non-consumable electrode in argon, and filler wire SvAMg6 of $2 \mathrm{~mm}$ diameter.

High-energy pulsed electric current treatment was applied along the welded seam at $5 \mathrm{~mm}$ intervals. Distribution of longitudinal residual stresses in the cross-section $\mathrm{C}$ of the welded butt joint, before and after treatment is shown in Fig. 6. It shows that EDT of welded joint leads to a significant reduction of residual stresses.

Control of residual distortion is another important challenge of the modern welding industry. This is an especially actual problem for welded thin-sheet metal constructions. EDT is a prospective approach to welded structures straightening. As shown above, the impact of high-energy current pulses on a welded joint leads to relaxation of the residual stresses that has influence on the residual distortion. The effect of electrodynamics treatment on residual deformation of welded structures was conducted on thin-sheet fragments of lining and load-carrying system of ship hulls up to $10 \mathrm{~m}$ length with 3-5 mm shell thickness, made of AMg6 alloy. After suffering service-induced shell damage, the structures were repaired using mechanical preparation of cracks and their subsequent welding. 


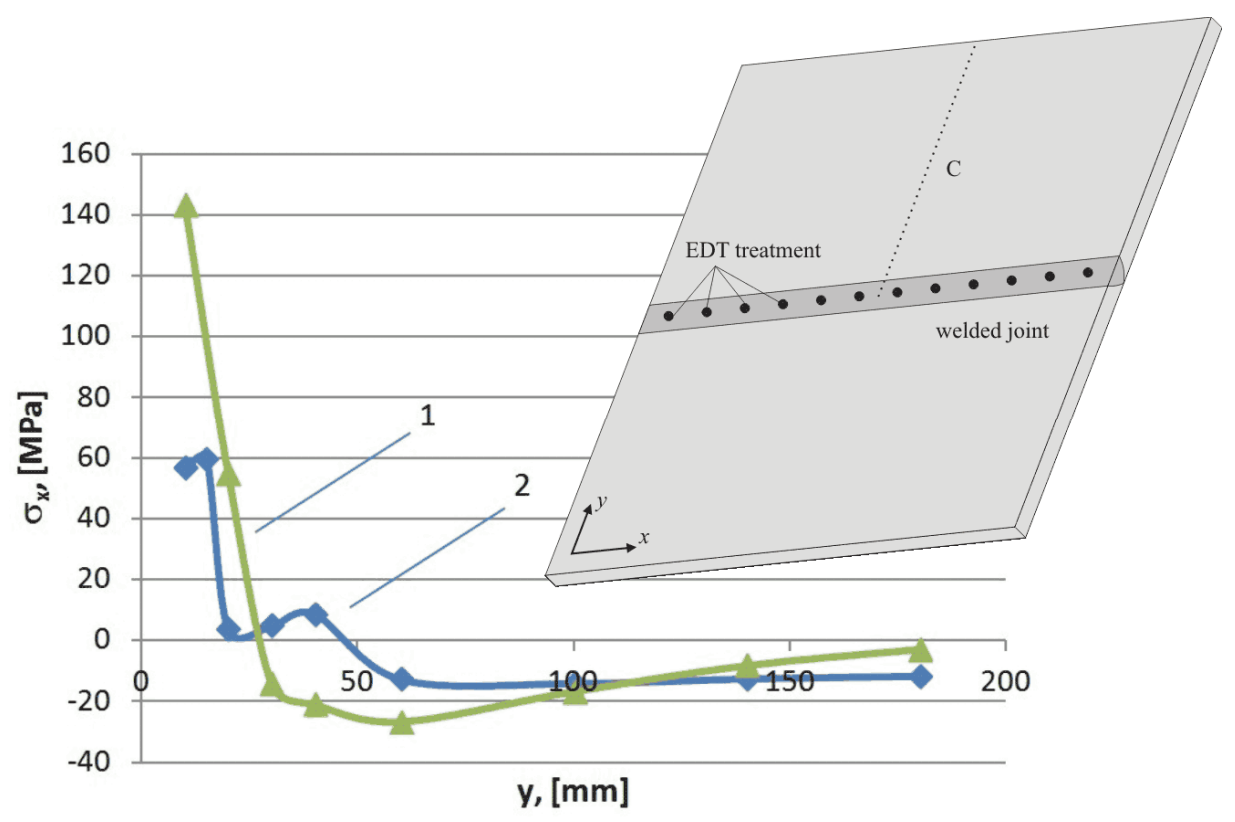

Fig. 6: Distribution of longitudinal residual stresses in cross section of non-processed (1) and processed (2) welded butt joint.

Repair welds of the load-carrying system were subjected to EDT to decrease the level of their warpage caused by welding. After repair welding, a longitudinal deformation with deflection of up to $15 \mathrm{~mm}$ was formed in the lateral stiffness of the bilge, making it impossible to provide planarity during assembly of the bottom lining. Electrodynamic treatment decreased the deflection of the lateral stiffness to $1.0 \mathrm{~mm}$ that allowed keeping its planarity with the bottom floor within required tolerances (Fig. 7a). The requirement for EDT of the shell was caused by a local buckling of the bottom in the repair welds with bending deflection of up to $8 \mathrm{~mm}$, which impaired the hydrodynamic characteristics of the ship. EDT allowed decreasing the residual deformations to virtually zero values (Fig. 7b).

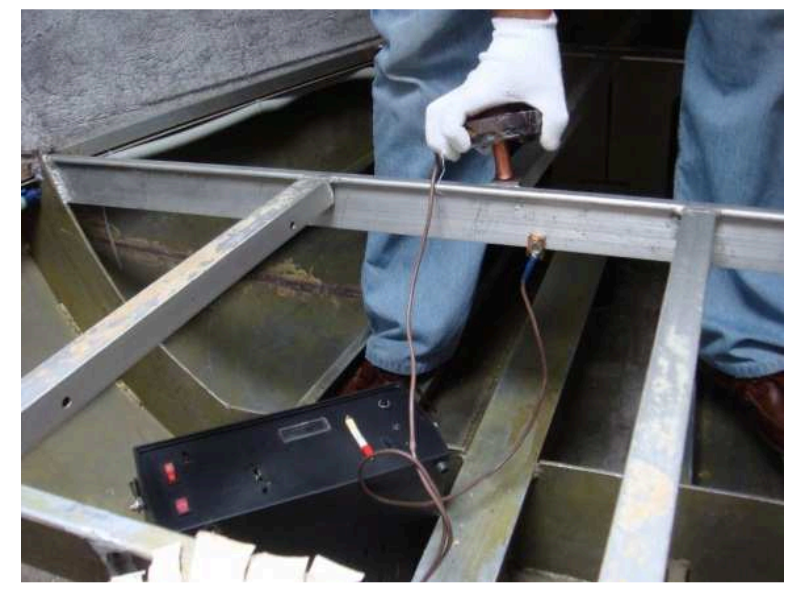

a)

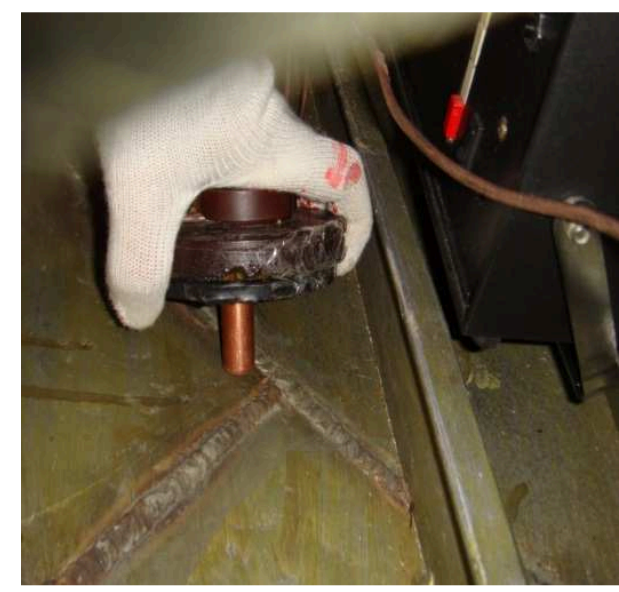

b)

Fig. 7: Welded joints subjected to EDT: a) the bottom lining; b) repair welds hull plating.

\section{Summary}

The presented results of investigations prove the efficiency of a high-density pulsed electric current treatment for non-destructive determination of residual stresses and controlling stressdeformed states of welded joints and structures. 


\section{References}

[1] L.M. Lobanov, V.I. Makhnenko, V.I. Trufiakov. Welded engineering structures. - K: Naukova Dumka, 1993.-Vol.1 - 416 p.

[2] K. Masubuchi. Analysis of welded structures residual stresses, distortion and their consequences. London.-Pergamon Press, 1980 - 642 p.

[3] D. Rodaj. Welding residual stresses and distortion.-Dusseldorf : DVS-Verlag, 2003.-397 p.

[4] L.M. Lobanov, B.S. Kasatkin, V.A. Pivtorak, S.G. Andrushchenko Determination of residual stresses by holographic interferography method using one hologram // Doklady AS USSR.1983.-Vol.271.-No.3.- pp. 557-561.

[5] A. Makino, D. Nelson Residual-stress determination by single-axis holographic interferometry and hole drilling - Part I: Theory / Exp.Mech.-1994.-34.- pp. 66-78.

[6] S.T. Lin, C.T. Hsieh, C.P. Hu. Two holographic blind-hole methods for measuring residual stresses. Exp.Mech.-1994.-34(2): pp.141-147.

[7] V.S. Pisarev, V.V. Balalov, V.S. Aistov, M.M. Bondarenko, M.G. Yustus. Reflection hologram interferometry combined with hole drilling technique as an effective tool for residual stresses fields investigation in thin-walled structures. Opt.Lasers Eng.-2001.-36(6): pp. 551-597.

[8] E. Ponslet, M.S teinzig Residual stress measurement using the hole drilling method and laser speckle interferometry. Part II: Analysis technique /Exp Techniques.-2003.-27(4): pp. 17-21.

[9] L.M. Lobanov, V.A. Pivtorak, V.V. Savitsky, G.I. Tkachuk Procedure for determination of residual stresses in welded joints and structural elements using electron speckleinterferometry/ The Paton Welding Journal. 1/2006, pp. 24-29.

[10] L. Lobanov, V. Pivtorak, V. Savitsky, G. Tkachuk Technology and Equipment for Determination of Residual Stresses in Welded Structures Based on the Application of Electron Speckle-Interferometry. Materials Science Forum, -2014, Vol. 768, pp. 166-173.

[11] L.M. Lobanov, V.A.Pivtorak, N.A.Pashchin et al. New methods of evaluation of technical state of welded joints, determination and control of residual stresses. Collection of scientific papers.- E.O. Paton Electric Welding Institute of NASU, 2006.-pp. 368-373.

[12] H. Conrad, "A Study into the Mechanisms for the Electroplastic Effect in Metals and Its Application to Metalworking, Processing and Fatigue", Final Report U. S. ARO Document DAAL03-86-K-0015, March 10, 1989. 